\title{
Drivers of Acceptance of a New Beverage in Europe
}

\author{
Ana Patricia Silva ${ }^{1,2, *}$, Maria Isabel Franco ${ }^{1}$, Cissé Mady ${ }^{3}$, Dominique Pallet ${ }^{4}$, Keith Tomlins ${ }^{5}$, \\ Ben Bennett ${ }^{5}$, Manuela Pintado ${ }^{1}$ and Miguel Sottomayor ${ }^{6}$ \\ 1 Laboratório Associado, Escola Superior de Biotecnologia, CBQF-Centro de Biotecnologia e Química Fina, \\ Universidade Católica Portuguesa, Rua Arquiteto Lobão Vital, 4202-401 Porto, Portugal; \\ isa_mfranco@yahoo.com (M.I.F.); mpintado@porto.ucp.pt (M.P.) \\ 2 Division of Human Nutrition, Wageningen University, Bomenweg 2, 6703 HD Wageningen, \\ The Netherlands (current affiliation) \\ 3 Laboratoire de Formation, Continue en Industries Agroalimentaires, Département Genie Cimique et \\ Biologie Appliquée, Université Cheikh Anta Diop (UCAD) de Dakar, BP 5085 Dakar-Fann, Senegal; \\ mady.cisse@ucad.edu.sn \\ 4 Centre de Coopération Internationale en Recherche Agronomique pour le Développement, UMR QualiSud, \\ Food Process Engineering Research Unit, 34398 Montpellier CIRAD, France; dominique.pallet@cirad.fr \\ 5 Natural Resources Institute, University of Greenwich, Chatham, Kent ME4 4TB, UK; \\ k.i.tomlins@greenwich.ac.uk (K.T.); ben.bennett@greenwich.ac.uk (B.B.) \\ 6 Faculdade de Economia e Gestão da Universidade Católica Portuguesa, Rua Diogo Botelho, \\ 1327 4169-005 Porto, Portugal; msottomayor@porto.ucp.pt \\ * Correspondence: apsilva@porto.ucp.pt; Tel.: +351-225-580-001
}

Academic Editor: Miranda Mirosa

Received: 22 April 2016; Accepted: 18 May 2016; Published: 25 May 2016

Abstract: One of the challenges of studying food consumption behavior is to identify the drivers of choice for a food product. This is particularly important to design and develop new foods for which no previous information is available. Hibiscus sabdariffa L. (Bissap) is an herbaceous plant and an important source of vitamins, minerals, and bioactive compounds, which confer a number of potential health benefits to derived products. The consumption of Bissap in beverage form is widespread in Africa and Asia, but not yet in Europe. Therefore, this study aimed to identify the main drivers of consumer acceptance of a traditional African beverage made from Bissap to which they had not been previously exposed. First, three focus groups $(n=22)$ were performed in Portugal to characterize the sensory profile of four Bissap beverages, to reveal perceptions and attitudes towards Bissap beverages, and to identify potential choice attributes. Subsequently, a full-profile conjoint analysis $(n=99)$ was performed, where consumers evaluated 37 Bissap beverage profiles, aiming to estimate choice attribute importance and to identify relevant market segments. Focus group findings showed that consumers would choose Bissap because they perceived as a healthy choice, and due to its novelty. The conjoint study showed an ideal profile for a Bissap beverage costing $€ 0.99 / \mathrm{L}$, $<18 \mathrm{kcal} / 100 \mathrm{~mL}$, packaged in Tetra-pack, light red color, and containing labeling information about antioxidants and Bissap. Four clusters of consumers were identified: price sensitive, body concerned, packaging attracted, and demanding, highlighting the most influential choice attributes: price, calories, and packaging. Findings provide useful guidance for new product development of an African product in the European lifestyle. Results might be useful from a nutraceutical point of view and to the food/beverages industry.

Keywords: Bissap; Africa; Portugal; consumer behavior; conjoint analysis; focus groups; segmentation

\section{Introduction}

Hibiscus sabdariffa L. is an herbaceous plant, cultivated largely in tropical and subtropical areas of the world and it is known by different names such as Roselle or Bissap among others 
(Mounigan and Badrie, 2006 [1]; Sáyago-Ayerdi et al., 2007 [2]; Hainida et al., 2008 [3]; Cisse, 2009 [4]). It is cultivated mainly for its calyces for the production of concentrates, jams and particularly for beverages. There are various recipes for beverage preparation, which can be consumed cold or hot (Sáyago-Ayerdi et al., 2007 [2]; Ramirez-Rodrigues et al., 2011 [5]). The consumption of Hibiscus sabdariffa L. (hereafter referred to as Bissap) in beverage form is widespread in Africa and Asia but not yet in Europe.

Bissap is an important source of vitamins, minerals, and bioactive compounds, such as organic acids, phytosterols, and polyphenols, some of them with antioxidant properties (Sáyago-Ayerdi et al., 2007 [2]). It is well known that these components are highly valued by the food industry because of their potential health benefits. Some pharmacological studies have been carried out with Hibiscus flowers, petals, and seeds, and several health benefits were identified such as cardio protective action, antihypertensive action, effectiveness against low-density lipoprotein oxidation, and hyperlipidaemia (Sáyago-Ayerdi et al., 2007 [2]; Hainida et al., 2008 [3]). Accordingly, the Bissap beverage might be classified as a functional beverage in the nutraceutical classification, as an herbal beverage or nutrition enhanced tea (Functional Food and Drinks, 2007 [6]). Sensorily, it is characterized by being astringent and strongly fruity (Bechoff et al., 2014 [7]).

How consumers evaluate their choices is affected by a complex set of factors that influence and shape decision process behavior (Blackwell et al., 2006 [8]). It has already been demonstrated that the chemical composition of Bissap beverages was related to sensory evaluation and acceptance of African and European consumers; in particular the anthocyanin content and Hibiscus taste. Three types of consumer behavior were identified being those who preferred syrup, those who preferred infusions, and those who preferred both. Each of these different groups of consumers the chemicals associated with acceptance differed; for example, acceptance of syrup likers was positively correlated to sweet taste, reducing sugar content and inversely correlated to acidic taste and titratable acidity while for infusion likers it was positively correlated to the taste of Hibiscus beverage and anthocyanin content (Bechoff et al., 2014 [7]).

Research on functional foods showed that health benefits and price are important drivers for purchase (Sparke and Menrad, 2009 [9]). Nevertheless, specifically for functional beverages, it has been shown that taste is the main motivating factor for consumption and not the health benefits (Sabbe et al., 2009 [10], Vidigal et al., 2011 [11]), although the perceived importance of food for health has increased significantly (Verbeke, 2006 [12]). According to a report on Functional Food and Drinks (FFD, 2007 [6]) the functional food market is characterized by three segments of consumers: (i) consumers for whom taste and convenience are fundamental, and health and nutritional benefits of secondary concern; (ii) health generalist consumers, who are regular purchasers of functional foods; (iii) medically driven purchasers, mostly comprising a population aged between 45 and 65 years. More recently, Grunert (2011) [13] reported four major dimensions of food quality for consumer acceptance of functional foods: taste and other sensory characteristics, healthiness, convenience and naturalness.

Along the same lines, it seems important to determine the drivers of acceptability of the Bissap beverage, a functional beverage according to its composition, in a European context, specifically in Portugal. Bissap is still an unfamiliar flavor in the European context, so, every effort needs to be made to support Bissap product development. Results on the identification of the major acceptance drivers of a Bissap beverage in Europe might be particularly interesting to the food industry, the nutraceutical industry and consumers in general. The development of a Bissap industry based on smallholder production in countries such as Senegal could be an important source of future income generation.

This study was performed with Portuguese consumers based on two stage methodology. Firstly, a qualitative study using focus groups aimed to: gain knowledge on the sensory general characterization of different types of Bissap beverage, and to determine the relevant choice attributes, possible occasions of consumption and usage for this kind of beverage. Secondly, a quantitative study using a conjoint analysis aimed to measure the importance of the salient consumer choice attributes of a Bissap beverage, and to reveal consumer segments with common preference profiles. Conjoint analysis is a powerful 
tool in modelling human decision making, as it enables the quantification of the weight consumers attach to various attributes when making their choice, predicting which products they will prefer, and enabling identification of distinct groups of consumers (Austin, 2000 [14]).

\section{Materials and Methods}

\subsection{Research Ethics}

The study was conducted in accordance with the Declaration of Helsinki, and the protocol was approved by project AFTER's Ethics Committee (project code 245025). Prior to the study, participants were informed about the aim of the study and procedures for handling personal data. In addition, they signed an informed consent, in which their voluntary participation was explicitly stated and also that they could withdraw from the study at any time. All tested samples were produced and prepared according to good hygiene and manufacturing practices.

\subsection{Qualitative Study-Focus Groups}

This first step aimed to collect evidence on consumer perceptions and attitudes towards a Bissap beverage. Data were collected through three focus group discussions, conducted according to standard procedures, using a script consistent with the above purpose for this research stage, and was video and tape recorded (Morgan, 1997 [15]). The themes surveyed throughout the focus groups are presented in Table 1.

Table 1. Topics addressed in focus group.

\begin{tabular}{l} 
Topics Addressed in the Focus Group \\
\hline 1. Sensory characterisation of Bissap beverage samples \\
2. Attitude to purchase \\
3. Occasions and places for consumption \\
4. Motivations for consumption \\
5. Willingness to pay \\
6. Places for purchase \\
7. Possible applications/usage \\
8. Influence of the African origin expressed on label \\
\hline
\end{tabular}

A pilot focus group was performed first to test the script which resulted in few adjustments to the script original version. Three focus groups $(90-100 \mathrm{~min})$ were then performed with 22 volunteers recruited in Catholic University. The recruitment criteria included two mandatory conditions: being fruit juice consumers and the persons responsible for the household groceries shopping. The participant profiles are presented in Table 2.

Table 2. Socio-demographic profile of the participants of the focus groups.

\begin{tabular}{lc}
\hline \multicolumn{1}{c}{ Socio-Demographics } & \% of Participants \\
\hline Male & $46 \%$ \\
Female & $54 \%$ \\
Age 18-25 & $36 \%$ \\
Age 26-55 & $36 \%$ \\
Age $>55$ & $27 \%$ \\
Single & $41 \%$ \\
Married & $59 \%$ \\
Higher education & $55 \%$ \\
Secondary education & $45 \%$ \\
Upper middle class * & $14 \%$ \\
Middle class * & $36 \%$ \\
\hline
\end{tabular}


Table 2. Cont.

\begin{tabular}{lc}
\hline \multicolumn{1}{c}{ Socio-Demographics } & \% of Participants \\
\hline Lower middle class * & $23 \%$ \\
Skilled workers * & $23 \%$ \\
Unskilled workers * & $5 \%$ \\
\hline
\end{tabular}

* According to ESOMAR classification [16].

The first task of the focus group participants was to taste and generally evaluate sensory attributes of four blind samples of Bissap beverage. A description of the Bissap beverage samples is presented in Table 3. Samples were presented to participants in coded transparent glasses. Water and crackers were also made available as a complement to the tasting. During the discussion participants were allowed to drink and taste the beverages as much as they wanted.

Table 3. Identification and preparation of the Bissap samples.

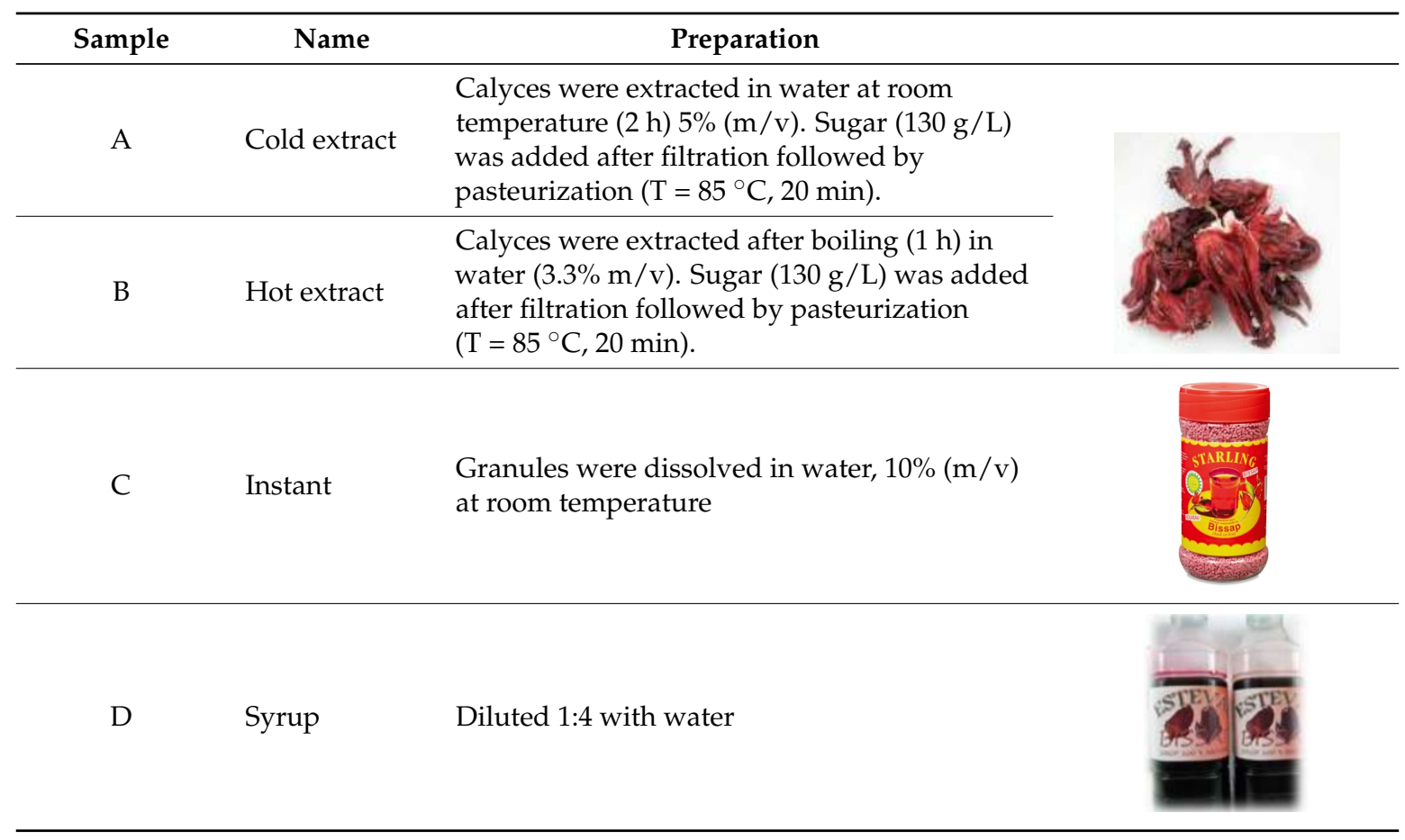

All data were transcribed verbatim, and the content analyzed using the software NVivo.

\subsection{Quantitative Study-Conjoint Analysis}

Global acceptability of food and beverages depends on the multi-attribute composition of the importance consumers' attach to each product attribute. For that reason, conjoint analysis was chosen as the theoretical and methodological framework for this study. This methodology has been widely used in food research, and its efficacy and usefulness has been clearly proven to the study of consumers' preferences and choice factors (e.g., pineapple juice, Finco et al., 2010 [17]; functional foods, Bech-Larsen and Grunert, 2003 [18]; wines, Gil and Sanchez, 1997 [19]; Quester and Smart, 1998 [20]; olives, Moskowitz et al., 2005 [21]; impact of reduced salt content, Hersleth et al., 2011 [22]; processed foods, Cardello et al., 2007 [23]; food bars, Mahanna et al., 2009 [24]).

In this study, the attributes and levels for the conjoint study model were defined according to the findings arising from the focus groups discussions. By using a fractional orthogonal plan created by the conjoint algorithm available in the software SPSS (version 19, IBM, New York, NY, USA), 37 full-profile Bissap beverages were produced. A questionnaire was written in which respondents 
have to evaluate their likelihood of purchasing a given hypothetical profile, by using five-point Likert scale. An example of a profile given to participants to perform the evaluation is presented in Figure 1. The questionnaire started with a brief introduction about the study aim and finished by asking for participants' socio-demographic information: age, gender, education, social grade, occupation, and frequency of juice consumption. The later information was used as a basis for segmentation. The questionnaire was conducted via the internet, and a sample of 107 responses was given, from which, however, only 99 were considered valid and useable in the analysis.

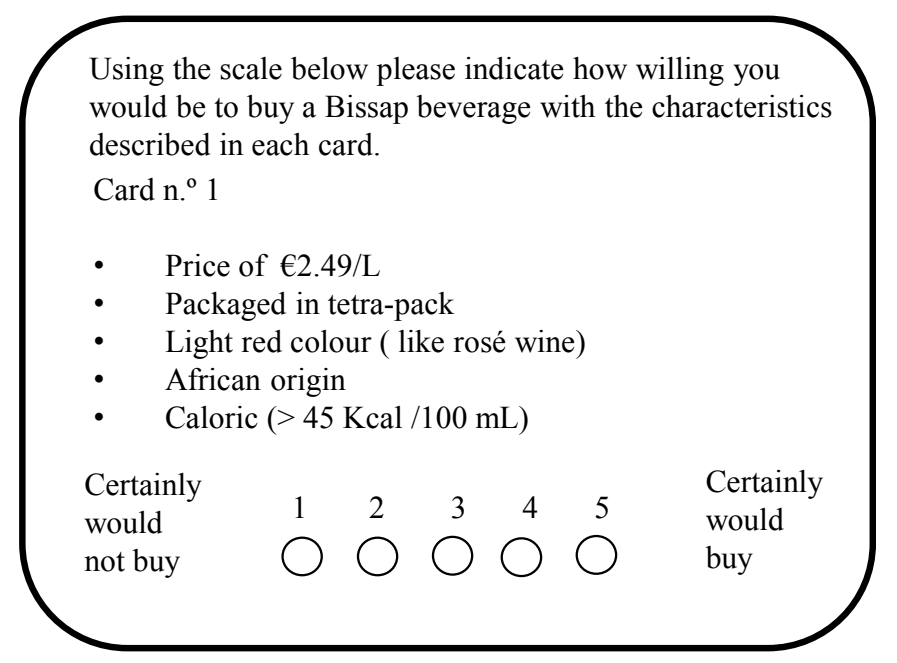

Figure 1. Example of a Bissap profile used for evaluation in the conjoint questionnaire.

\section{Results and Discussion}

\subsection{Qualitative Study-Focus Groups}

\subsubsection{Global Sensory Characterization of Bissap Beverages}

The focus groups' discussions started with a blind tasting session with four different samples of Bissap. Out of all the samples the favourite was sample C (instant), followed by sample B (hot extract), sample D (syrup), and the least favourite was sample A (cold extract). Briefly, a characterization of each sample is presented below based on participants' statements. Sample A (cold extract) was perceived as a winter season beverage and classified as very sweet, with a strong flavor, an unpleasant aroma, dark and artificially colored, with a very acidic aftertaste. Sample B (hot extract) was considered similar in flavor to sample A, that is, also very sweet with an acidic aftertaste, with an unpleasant aroma, but with a suitable color. Interestingly, two participants (out of 22) identified this sample as Hibiscus. Sample C (instant) was perceived as a summer beverage and classified as having a balanced and good pleasant flavor, which was associated with pomegranate. On the other hand the later sample was also classified as watery and negatively rated for its general appearance, particularly its color. Sample D (syrup) was classified as very sweet, with a flavor similar to sample $C$ and with a reasonably acceptable color. It might be concluded at this point that participants were able to distinguish between the four samples. Overall, all the samples seemed to have a sugar content higher than participant preference. Participants expected a healthy beverage, and considered too high sugar content inconsistent with this goal, as this would negatively affect health. This characteristic is then considered a disadvantage for this beverage, and this should be noted in further product development. There is a general perception that people could readily become familiarized with the Bissap flavor and learn to enjoy it. A general sensory appreciation of Bissap beverage is summarized in Table 4, where all the positive and negative evaluations of the attributes are listed. 
Table 4. Frequency of the attributes generated during the focus groups.

\begin{tabular}{llc}
\hline \multicolumn{1}{c}{ Classification } & \multicolumn{1}{c}{ Attributes } & Frequency (\%) \\
\hline \multirow{4}{*}{ Sensory } & Sweetness & $64 \%$ \\
& Astringency & $32 \%$ \\
& Acid & $32 \%$ \\
& Watery & $23 \%$ \\
& Bitter & $23 \%$ \\
\hline \multirow{5}{*}{ Food Positive } & Pomegranate & $100 \%$ \\
& Fruity & $23 \%$ \\
& Cranberry/Blackberry & $18 \%$ \\
& Hibiscus & $14 \%$ \\
& Blackcurrant & $14 \%$ \\
& Tomato & $9 \%$ \\
Food Negative & Cherry & $9 \%$ \\
& Sour Cherry & $5 \%$ \\
\multirow{2}{*}{ Non-Food Negative } & Wine & $9 \%$ \\
& Syrup/Medication & $18 \%$ \\
& Poison & $5 \%$ \\
& Plastic & $5 \%$ \\
\hline
\end{tabular}

\subsubsection{Attitude to Purchase}

Assuming that this beverage would be available on the market, participants were asked on their willingness to buy the product, and how frequently. The results showed that almost half the participants (46\%) stated they would be willing to buy the Bissap beverage two to three times a week; $36 \%$ between one and two times a month; $9 \%$ would buy it sporadically; $5 \%$ once a week; and $5 \%$ would never buy it.

\subsubsection{Occasions and Places for Consumption}

Table 5 summarizes the main occasions and places for consumption if the Bissap beverage were available on the market. The results are presented in percentages representing a ratio of the number of participants who stated that particular occasion/place and the total number of participants.

Table 5. Identified occasions and places for Bissap beverage consumption (frequency \%).

\begin{tabular}{lc}
\hline \multicolumn{1}{c}{ Occasions } & Frequency (\%) \\
\hline Breakfast & $50 \%$ \\
Lunch & $41 \%$ \\
Mid afternoon & $64 \%$ \\
Dinner & $32 \%$ \\
\hline \multicolumn{1}{c}{ Places } & Frequency (\%) \\
\hline Home & $95 \%$ \\
Terrace & $50 \%$ \\
Café/bar & $50 \%$ \\
Macrobiotic restaurant & $41 \%$ \\
Spa & $27 \%$ \\
Gym & $23 \%$ \\
Hotel & $14 \%$ \\
\hline
\end{tabular}

\subsubsection{Motivations for Consumption}

The main motivations to drink Bissap by a sample of Portuguese consumers are presented in Figure 2. Potential health benefits were the main reason mentioned by Portuguese consumers for drinking the Bissap beverage. This motivation is mostly given by women $(75 \%)$, opposed to sensory 
properties which men valued more $(90 \%)$. Novelty is also an important factor for both genders $(50 \%$ each). Participants were told beforehand that this beverage is rich in antioxidant components, and as these components might be important for health, it seems they would be willing to drink it even if the flavor is not as pleasant as they expected. This finding is in line with the results of Sparke and Menrad (2009) [9], where health is also identified as one relevant motivation for the consumption of functional beverages. Flavor and perceived health benefits are two important considerations for food acceptance and it has been discussed in the functional foods context by some authors. According to Verbeke (2006) [12], as a general rule, consumers are hardly willing to compromise functional food taste for health. Sabbe et al., (2009) [10] concluded that Belgian consumer acceptance and intention to purchase açaí fruit juices is mostly driven by sensory pleasure rather than recognized health benefits.

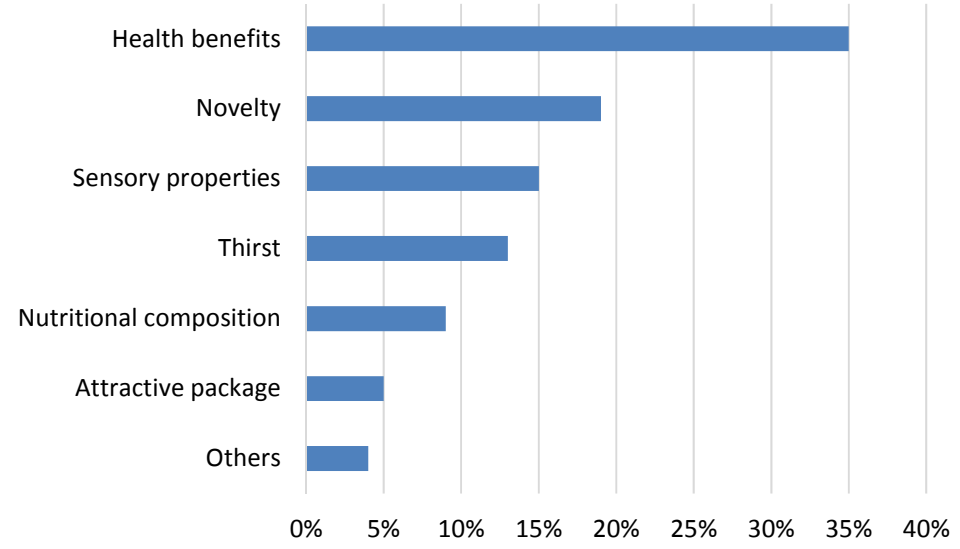

Figure 2. Reasons for consumption of Bissap beverage by Portuguese consumers.

\subsubsection{Willingness to Pay}

Regarding the willingness to pay for the Bissap beverage, about $60 \%$ of the participants would buy $1 \mathrm{~L}$ packages in the supermarkets and the range of prices should be between $€ 0.70$ and $€ 2 / \mathrm{L}$, although for the majority the range was smaller and should be between $€ 1.5$ and $€ 2 / \mathrm{L}$. The remaining $40 \%$ would buy smaller packages instead, say $0.33 \mathrm{cl}$ packages, in specific spots within supermarkets, cafés, and bars. For this group right prices would vary between $€ 0.35$ and $€ 0.50$, to be paid in supermarkets, and $€ 0.8$ and $€ 1.00$ in cafés or bars.

Packaging had an impact on product choice too. Participants spontaneously highlighted their preferences for packaging material: $14 \%$ would prefer glass bottles for this type of beverage, while the majority of participants would prefer tetra-pack packaging. Cans were referred to as unsuitable for this type of beverage. Some participants also mentioned that they would be willing to pay a premium for very attractive packaging, on the condition that the packaging labelling includes relevant information on the product, particularly credible information on this beverage, namely the high antioxidant capacity.

\subsubsection{Places for Purchase}

This topic covers the places where consumers would like to have the Bissap beverage available for purchase. Almost all participants would like to buy it in supermarkets $(82 \%)$, cafés (27\%), bars $(23 \%)$, and restaurants $(9 \%)$. In addition, convenience shops, pharmacies, and petrol station shops were also mentioned by $5 \%$ of participants.

\subsubsection{Possible Applications/Usages}

This topic surveyed consumers' ideas and perceptions on the possible uses of the Bissap flavor in food processing. Table 6 summarises the uses proposed by participants and the frequency of proposed 
use. According to participants' views, Bissap might not only have great potential to be used in food industry applications, but also for home-made applications. Most suggestions are related to sweet foods (desserts) and to beverages.

Table 6. Possible applications of Bissap in food.

\begin{tabular}{llc}
\hline \multicolumn{1}{c}{ Applications Type } & Product Suggestion & Frequency \\
\hline \multirow{3}{*}{ Food industry } & Yogurt & $27 \%$ \\
& Gelatin & $23 \%$ \\
& Ice-creams & $18 \%$ \\
& To mix with & $14 \%$ \\
& non-alcoholic beverages & $5 \%$ \\
\hline \multirow{3}{*}{ Home-made } & To make Sangria & $50 \%$ \\
& Topping/Dressing & $41 \%$ \\
& Jelly & $5 \%$ \\
\hline
\end{tabular}

\subsubsection{Influence of the African Origin Expressed on Label}

This topic surveyed participants' opinion on the effect of the disclosure on labelling the Bissap as a product of African origin. The concern was that the Portuguese market might have a negative perception of foods of African origin. It was observed that consumers are split in two different clusters in this matter. The minority ( $9 \%-$ men aged 18 to 25$)$, think that labels and labelling information, are not at all important, because consumers' like themselves do not read or look at it at all; so for them it does not really matter whether the product origin is mentioned. For the majority of participants $(81 \%)$ however, there is a general agreement on the importance of labelling information, especially relating to the product's geographical origin (Africa). One of the reasons given is because they like to be informed about the product, knowing its origin, or even getting some extra background information. Another reason also referred to was because Africa has a less intensive agriculture, not overusing pesticides, for example, and some consumers can link this to healthier agricultural products, which means that this information might even add consumer value to the product. Additionally, it was also mentioned that since Africa is very much associated with charity campaigns, it could be an advantage to include this information on labelling, as it would increase the consumer choice likelihood. Summarizing, the research showed a positive response to the Africaness of the product.

\subsection{Quantitative Study-Conjoint Analysis}

\subsubsection{Most Important Attributes and Ideal Profile}

The findings from the focus groups were used as input for the first step of conjoint analysis. The attributes and levels decided are presented in Table 7. The levels are the alternative intensities assumed for the attributes. Based on the evaluation by the participants of the hypothetical product profiles, and applying the Conjoint Module of the Statistical software package SPSS 19, the relative importance that participants attach to each attribute and the utility they attach to the levels of these attributes were estimated. The results are presented in Table 7. For interpretation of the utility it is worth knowing that a higher value means that the attribute, or attribute level, is more important to the respondents (Malhotra, 1996 [25]). All the attributes were classified as discrete variables, although a negative linearity for price could also have been assumed, as the lower the price, the higher the benefit for the consumers; nevertheless the results did not differ significantly. 
Table 7. Conjoint analysis results: relative importance of the attributes and utilities of the levels.

\begin{tabular}{llc}
\hline Relative Importance of the Attributes (\%) & \multicolumn{1}{c}{ Levels } & Utilities \\
\hline \multirow{3}{*}{ Price-29\% } & $€ 0.99 / \mathrm{L}$ & 0.343 \\
& $€ 1.49 / \mathrm{L}$ & 0.155 \\
& $€ 1.99 / \mathrm{L}$ & -0.026 \\
& $€ 2.49 / \mathrm{L}$ & -0.472 \\
\hline \multirow{2}{*}{ Beverage color-6\% } & Dark red color (like red wine) & -0.004 \\
& Light red color (like rosé wine) & 0.004 \\
\hline \multirow{2}{*}{ Calories-24\% } & Light caloric (less than $18 \mathrm{kcal} / 100 \mathrm{~mL}$ ) & 0.153 \\
& Low caloric (between 19 and $32 \mathrm{kcal} / 100 \mathrm{~mL})$ & 0.158 \\
& Slightly caloric (between 33 and $45 \mathrm{kcal} / 100 \mathrm{~mL})$ & -0.079 \\
& Caloric (more than 45 kcal/100 $\mathrm{mL}$ ) & -0.233 \\
\hline \multirow{2}{*}{ Antioxidant information-6\% } & With antioxidant information & 0.033 \\
& Without antioxidant information & -0.033 \\
\hline \multirow{2}{*}{ Packaging-24\% } & Can & -0.081 \\
& Glass & 0.049 \\
& Plastic & -0.071 \\
Bissap Information-6\% & Tetra-pack & 0.104 \\
\hline \multirow{2}{*}{ Origin Information-5\% } & Made with Bissap & 0.049 \\
& Without reference to Bissap & -0.049 \\
\hline
\end{tabular}

The most noticeably important attribute for these sample of Portuguese consumers related to the Bissap beverage was price, which had the highest relative importance (29\%). This is not so surprising because price is an important determinant of food choices and purchases. In others studies conducted with a similar methodology, price has been the attribute most valued by consumers for different products (Finco et al., 2010 [17]; Mesías et al., 2011 [26]) and also as the major constraining for non-consumers not buying functional beverages (Sparke and Menrad, 2009 [9]). As would be expected, there is an inverse relation between price and utility, as the higher the price the lower utility. Consumer likelihood of purchase is also significantly affected by the nutritional value (the number of calories), and the relative importance for this attribute reached $24 \%$. In this case the low nutritional value is perceived as health related since lower calories would lead to weight loss, as it would explain the observed inverse relation between utility and the number of calories. Also with a relative importance of $24 \%$ came packaging, i.e., packaging material. It is interesting to note that for this group of consumers the packaging information is not as important as antioxidant information $(6 \%)$, Bissap information (6\%) or the reference to the African origin (5\%) of the product. This is consistent with the evidence reported by Sparke and Menard (2009) [9] for a functional orange juice: packaging holds a relative importance higher than the health claims. A possible explanation for this is given by Bech-Larsen and Grunert (2003) [18], suggesting that the perception of the healthiness of functional foods is more dependent on perception of the product's nutritional qualities than on any type of health claim. Among the attributes evaluated, the color also does not seem to be a relevant one for purchasing intention since its relative importance is $6 \%$.

The preferred Bissap beverage profile is determined with the high utility of each level for each attribute. In this case, it corresponds to a price of $€ 0.99 / \mathrm{L}$, light caloric (less than $18 \mathrm{kcal} / 100 \mathrm{~mL}$ ), tetra-pack package, light red color, with antioxidant information and Bissap information on the labelling. This group of consumers did not value the information about the African origin of the beverage.

The consistency of the participants' responses, i.e., that the model fits individual data, can be evaluated by calculating the Pearson correlation coefficient $(R)$ between the original ratings given by respondents and those determined by the model (Malhotra, 1996 [25]). The value of $R$ is $=0.972$ $(p<0.001)$ indicating that the model predicted the participant preferences well. Also the Kendall's tau for Holdouts coefficient, which is an indicator of internal validity, has a high value of $0.914(p<0.001)$, which indicates a good predictive ability. 


\subsubsection{Consumer Performance Segmentation}

The market segmentation is the process of finding groups of similar consumers in terms of some specific criteria of relevance to the product strategic context (Lilien et al., 2007 [27]). In this study, a cluster analysis was applied in order to classify participants into homogenous preference clusters.

The calculations were performed with the cluster module of the statistical software package SPSS 19 , using first a hierarchical cluster analysis and Ward's distance method, and then a non-hierarchical clustering procedure, the k-means cluster procedure. The inputs used were the utilities for each participant. A four-cluster solution was selected as being the one optimizing similarity within clusters and dissimilarity between clusters. The results are presented in Table 8. In bold are the highest utilities for each cluster, and these values were used to discriminate and profile the clusters. An analysis of variance of the utilities showed that cluster preferences did not differ significantly with respect to the attributes: color, antioxidant information, Bissap information, and information about African origin, but did differ significantly in relation to the attributes: price, calories, and packaging; for this reason they are marked * in Table 8.

Table 8. Profiling performance of each cluster (utilities of levels).

\begin{tabular}{|c|c|c|c|c|}
\hline \multirow{2}{*}{ Levels } & \multicolumn{4}{|c|}{ Cluster } \\
\hline & $1(n=27)$ & $2(n=17)$ & $3(n=12)$ & $4(n=43)$ \\
\hline$€ 0.99 / \mathrm{L}^{*}$ & 0.830 & 0.410 & 0.080 & 0.080 \\
\hline$€ 1.49 / \mathrm{L}^{*}$ & 0.280 & 0.130 & 0.050 & 0.110 \\
\hline$€ 1.99 / \mathrm{L} *$ & -0.140 & -0.040 & 0.070 & 0.020 \\
\hline$€ 2.49 / \mathrm{L}^{*}$ & -0.980 & -0.500 & -0.210 & -0.220 \\
\hline Dark red color (like red wine) & -0.020 & -0.040 & 0.070 & $-1 \times 10^{-16}$ \\
\hline Light red color (like rosé wine) & 0.020 & 0.040 & -0.070 & $1 \times 10^{-16}$ \\
\hline Light caloric (less than $18 \mathrm{kcal} / 100 \mathrm{~mL}$ ) * & 0.050 & 0.950 & -0.310 & 0.040 \\
\hline Low caloric (between 19 and $32 \mathrm{kcal} / 100 \mathrm{~mL}$ ) & 0.110 & 0.330 & 0.170 & 0.120 \\
\hline Slightly caloric (between 33 and $45 \mathrm{kcal} / 100 \mathrm{~mL}$ ) & -0.060 & -0.410 & 0.250 & -0.050 \\
\hline Caloric (more than $45 \mathrm{kcal} / 100 \mathrm{~mL}$ ) * & -0.090 & -0.870 & -0.100 & -0.110 \\
\hline With antioxidant information & 0.030 & 0.050 & -0.010 & 0.040 \\
\hline Without antioxidant information & -0.030 & -0.050 & 0.010 & -0.040 \\
\hline Can * & -0.150 & -0.020 & 0.240 & -0.150 \\
\hline Glass * & -0.040 & -0.050 & 0.410 & 0.040 \\
\hline Plastic & -0.010 & 0.010 & -0.130 & -0.120 \\
\hline Tetra-pack* & 0.200 & 0.060 & -0.520 & 0.230 \\
\hline Made with Bissap & 0.050 & 0.020 & 0.030 & 0.070 \\
\hline Without reference to Bissap & -0.050 & -0.020 & -0.030 & -0.070 \\
\hline African origin & -0.020 & -0.040 & 0.010 & -0.020 \\
\hline Without information about the beverage origin & 0.020 & 0.040 & -0.010 & 0.020 \\
\hline
\end{tabular}

${ }^{*}$ Levels that differ significantly $(p<0.05)$.

Cluster 1 ( $n=27$ ) shows that price has the highest relative importance. For this cluster the relative importance of all other attributes (except packaging) are close to each other and far less important than price. We called this consumer segment the price sensitive consumers. Cluster 2 amounts to about one-fifth of the participants $(n=17)$ and is the group showing the highest relative importance of calories. Besides price, which is in second position for this cluster, all the other attributes are not so relevant and are therefore less choice influential for this type of consumers. We called this group the body concerned consumers. Cluster 3 is the smallest cluster $(n=12)$, and for this group the most important attribute is clearly packaging. All the other attributes have lower (and similar) relative importance. We called this segment the packaging attracted consumers. Cluster 4 encompasses the greatest fraction of participants $(n=45)$. For this segment three different attributes presents similar importance: price, packaging, and calories. For this reason, this segment was called the demanding consumers, because they probably look for the best combination of those three attributes during purchase. An ideal profile of a Bissap beverage for each cluster was defined by identifying the optimal combination of the levels of the attributes according to the fitted preferences model, and is given in Figure 3. The ideal Bissap profile for clusters 1 and 2 only differ in the desirable number of calories. The difference between clusters 1 and 4 is the desirable price and the differences between clusters 2 and 4 are the price and the number of calories. The most different Bissap profile is achieved by cluster 3 
which only has price in common with clusters 1 and 2 . It seems that there is a consensus between all clusters where the information made with Bissap is indeed influential for product choice.

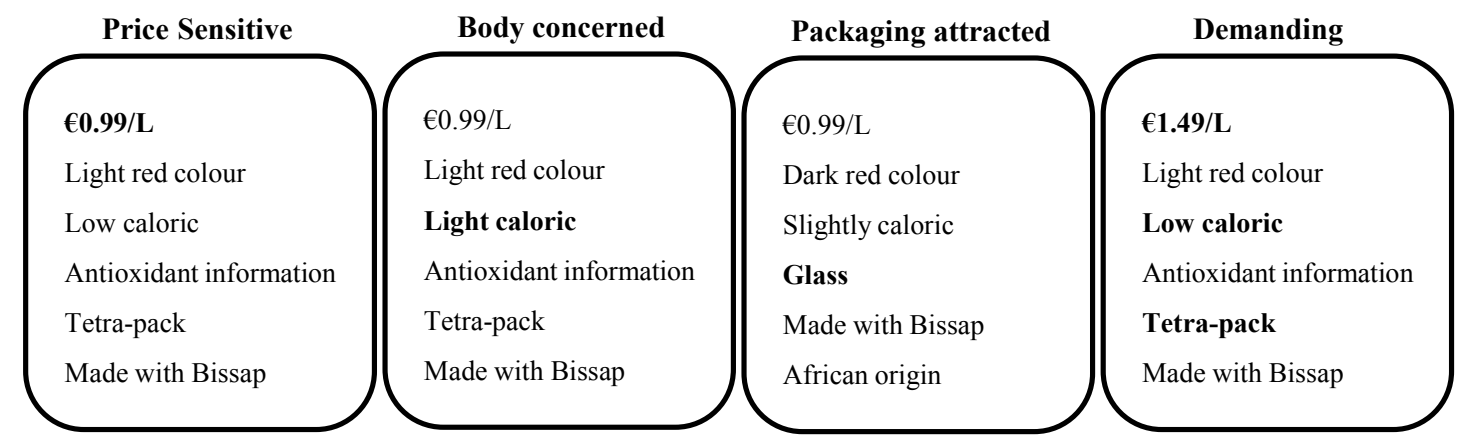

Figure 3. Optimal combination of attributes: ideal profile of Bissap beverage for each cluster.

Bechoff et al., (2014) [7] explored cluster analysis based on acceptance only. This revealed different clusters related to liking of syrups, infusions, or liking both and this was related to color and taste characteristics and associated chemical constituents. Analyzing those clusters with the ones achieved on this study, it could be inferred that body concerned consumers might be infusion likers, since calories are shown to be most important attribute and they value the antioxidant information, which is congruent with the concept of infusion. This research suggests that adding other factors related to purchase can give different and revealing results. For market segmentation, it is important to find characteristics enabling discrimination between clusters. The four clusters are therefore described in terms of their socio-demographic characteristics and consumption habits (frequency of juice consumption) in Table 9, as a complement to the preference profiling for each one.

Table 9. Characterization of the participants assigned to each cluster identified in the conjoint study (in percentage).

\begin{tabular}{|c|c|c|c|c|c|c|}
\hline & \multirow{2}{*}{ Variables } & \multicolumn{4}{|c|}{ Cluster } & \multirow{2}{*}{$x^{2}$} \\
\hline & & 1 & 2 & 3 & 4 & \\
\hline \multirow{2}{*}{ Gender } & Female & $63 \%$ & $71 \%$ & $42 \%$ & $49 \%$ & \multirow{2}{*}{$\begin{array}{l}3.879 \\
\text { (NS) }\end{array}$} \\
\hline & Male & $37 \%$ & $29 \%$ & $58 \%$ & $51 \%$ & \\
\hline \multirow{2}{*}{ Age (Years) } & 18 to 36 & $37 \%$ & $47 \%$ & $58 \%$ & $44 \%$ & \multirow{2}{*}{$\begin{array}{l}1.586 \\
\text { (NS) }\end{array}$} \\
\hline & 37 to 58 & $63 \%$ & $53 \%$ & $42 \%$ & $56 \%$ & \\
\hline \multirow{3}{*}{ Education } & Masters/PhD & $30 \%$ & $41 \%$ & $33 \%$ & $30 \%$ & \multirow{3}{*}{$\begin{array}{c}3.932 \\
\text { (NS) }\end{array}$} \\
\hline & Graduate & $41 \%$ & $52 \%$ & $50 \%$ & $49 \%$ & \\
\hline & Secondary school or lower & $29 \%$ & $6 \%$ & $17 \%$ & $21 \%$ & \\
\hline \multirow{5}{*}{ Social Grade } & Upper middle class & $22 \%$ & $35 \%$ & $17 \%$ & $26 \%$ & \multirow{5}{*}{$\begin{array}{c}9.683 \\
\text { (NS) }\end{array}$} \\
\hline & Middle class & $41 \%$ & $35 \%$ & $58 \%$ & $49 \%$ & \\
\hline & Lower middle Class & $26 \%$ & $18 \%$ & $17 \%$ & $16 \%$ & \\
\hline & Skilled workers & $11 \%$ & $6 \%$ & $8 \%$ & $7 \%$ & \\
\hline & Unskilled workers & $0 \%$ & $6 \%$ & $0 \%$ & $2 \%$ & \\
\hline \multirow{3}{*}{ Occupation } & Employed/Student & $65 \%$ & $47 \%$ & $84 \%$ & $76 \%$ & \multirow{3}{*}{$\begin{array}{c}10.155 \\
\text { (NS) }\end{array}$} \\
\hline & Self-employed/Manager & $23 \%$ & $35 \%$ & $8 \%$ & $24 \%$ & \\
\hline & Unemployed & $12 \%$ & $18 \%$ & $8 \%$ & $0 \%$ & \\
\hline \multirow{2}{*}{ Main income earner } & Yes & $52 \%$ & $53 \%$ & $50 \%$ & $44 \%$ & \multirow{2}{*}{$\begin{array}{l}0.587 \\
\text { (NS) }\end{array}$} \\
\hline & No & $48 \%$ & $47 \%$ & $50 \%$ & $56 \%$ & \\
\hline \multirow{3}{*}{ Households } & 1 or 2 persons & $22 \%$ & $53 \%$ & $25 \%$ & $28 \%$ & \multirow{3}{*}{$\begin{array}{r}5.622 \\
\text { (NS) }\end{array}$} \\
\hline & $3-4$ persons & $63 \%$ & $41 \%$ & $67 \%$ & $60 \%$ & \\
\hline & 5 persons or more & $15 \%$ & $6 \%$ & $8 \%$ & $12 \%$ & \\
\hline \multirow{3}{*}{$\begin{array}{l}\text { Frequency of juices } \\
\text { consumption }\end{array}$} & Daily to 4 times/week & $44 \%$ & $41 \%$ & $33 \%$ & $51 \%$ & \multirow{3}{*}{$\begin{array}{r}2.865 \\
(\mathrm{NS})\end{array}$} \\
\hline & 1 to 3 times/month & $48 \%$ & $41 \%$ & $58 \%$ & $40 \%$ & \\
\hline & Less than once a month & $8 \%$ & $18 \%$ & $9 \%$ & $9 \%$ & \\
\hline
\end{tabular}


The main characteristics of each cluster are: Cluster 1-price sensitive-is characterized as being mostly women, aged over 37. Cluster 2-body concerned - this group includes mostly women and consumers with the lowest frequency of juice consumption. Cluster 3-packaging attracted - this cluster includes mostly men, aged less than 37 years, who have consumed juice between one and three times a month. Cluster 4-demanding - this cluster is characterized by consumers that are not the main income earner, belonging to middle class or above, and having the highest frequency of juice consumption.

Despite the identification of four different preference clusters and profiling them, it was not possible to find significant differences (according to the Chi-square tests done) between the clusters on their descriptors. With the characteristics covered by this study, it was possible to establish that heterogeneity between clusters was not found at a significant level, and that is a necessary criterion to be met if one is to find a relevant segmentation (Lilien et al., 2007 [27]). Maybe using a larger sample and/or different characteristics or attitudes related to the participants could achieve such significant differences. So, further studies are required to find out if there are significantly different segments.

\section{Discussion between the Focus Groups and Conjoint Analysis Results}

Based on the results, it was not possible to conclude the relevance of the information on the African origin expressed on the packaging. According to the perception expressed by the majority of consumers in the focus groups this attribute was classified as very important, adding value to the product, and positively affecting purchase. However when this attribute was assessed within a full product profile, in combination with other attributes, and consumers are forced to indicate their likelihood to purchase, the relative importance of this attribute decreased to the point of becoming the lowest priority. Further studies should explore this issue for better clarification.

The price of $€ 0.99 / \mathrm{L}$ in the conjoint study was shown to be the most relevant attribute, and one cluster was even called the price sensitive consumers. In the focus group consumers said they were willing to pay between $€ 1.5 / \mathrm{L}$ and $€ 2 / \mathrm{L}$, or even more for more attractive packaging and if the possible health benefits of Bissap were credibly displayed. In the focus groups, consumers experienced the beverage, i.e., they saw, talked about, and tasted the beverage and this experience might be the reason why they stated they would be willing to pay more at the time. In addition, the focus groups' discussions were context related, which is an important factor to attach to an attribute such as the price. Another relevant issue in focus groups can be the fact that participants share opinions within a group and some sensitive social issues may be affected, namely the price.

Another important outcome from both methods is the perception of high sugar levels evaluated during the tasting in the focus groups, which is confirmed by a desirable light or low caloric beverage in the conjoint study. This makes sense when the main motivation for Bissap beverage consumption is the perceived health benefits, and the body concerned cluster is identified by the conjoint study. What is not so clear is the lowest importance attached to the antioxidant information in the conjoint study, but again, a forced choice between product profiles gives priority to what is indeed the most relevant attribute.

Packaging also appears to be a relevant attribute in both methods and this outcome is therefore in agreement. It seems clear that tetra-pack and glass are the most suitable type of packaging for this beverage, while cans are perceived as unsuitable.

\section{Limitations and Further Studies}

This study was performed in Portugal with a convenient and relatively small sample of participants. So, the results obtained are obviously not generalizable to the whole population. So, in order to achieve cross-cultural validation, further studies in other European countries should be performed, using larger sample sizes. Also, a smaller number of Bissap beverage profiles (combination of attributes) should be tested such as sensory related ones. As significant differences between the four segments, by using the socio-economic variables and the frequency of juice consumption, were not achieved, other variables should be tested to gain more knowledge about the possible segments of 
Bissap drinkers. Results from the qualitative and quantitative studies were shown to be inconclusive to some extent and for some aspects; this might be due to the fact that the quantitative studies were performed with a hypothetical product. In addition, the effects of food neophobia should be investigated, as Bissap is relatively unfamiliar taste to Europeans. It would be interesting to use the insights from this study to reengineer the Bissap beverage and to include sensory evaluation, food neophobia, and product imaging together in future studies.

\section{Conclusions}

Bissap beverage is not commonly consumed in Europe and is largely unknown to the general population. Due to its nutritional composition, it may have great potential to be considered as a functional beverage, and this probably increases its consumer value and market acceptability. In the field of consumer food behavior studies, one of the major challenges is to identify the key factors for consumer acceptance and choice, so this study encompasses this goal, focusing on a Bissap beverage for Portuguese consumers. Despite being unfamiliar with the Bissap flavor, the global sensory appreciation of Portuguese consumers of this beverage is mostly positive. Also important insights were given for the reengineering of the Bissap beverage in a European context. This study shows that the original beverage has high sugar content and that consumers value more a light/low caloric beverage. In addition, the actual composition does not seem to be compatible with a heathy beverage concept. The four clusters of consumers identified are well discriminated in terms of their preferences: price sensitive, body concerned, packaging attracted, and demanding. These clusters confirm and highlight the most relevant attributes for the choice of Bissap beverage: price, calories, and packaging.

The findings of this study encourage further studies to gain and disseminate more knowledge on the acceptability of the Bissap beverage on the European market.

Acknowledgments: This study was performed within the European Seven Framework programme (EU FP7), and is part of the AFTER project (African Food Tradition Revisited by Research) under contract no. 245025. Funding of the study by the European Commission is gratefully acknowledged. More information about the project can be found on http://www.after-fp7.eu/en/. This work was supported by National Funds from FCT through project PEst-OE/EQB/LA0016/2013. The authors warmly thank Ana Isabel Costa and Hans-Peter Voss for their valuable comments on this paper.

Author Contributions: Dominique Pallet, Keith Tomlins, Ben Bennett, Manuela Pintado, and Ana Patricia Silva conceived and designed the experiments; Ana Patricia Silva and Isabel Franco performed the experiments; Ana Patricia Silva and Miguel Sottomayor analyzed the data; Cissé Mady contributed with the samples and sample preparation; Ana Patricia Silva wrote the paper.

Conflicts of Interest: The authors declare no conflict of interest.

\section{References}

1. Mounigan, P.; Badrie, N. Roselle/sorrel (Hibiscus subdariffa L.) wines with varying calyx puree and total soluble solids: Sensory acceptance, quantitative descriptive and physicochemical analysis. J. Foodserv. 2006, $17,102-110$.

2. Sáyago-Ayerdi, S.; Arranz, S.; Serrano, J.; Goni, I. Dietary Fiber Content and Associated Antioxidant Compounds in Roselle Flower (Hibiscus sabdariffa L.) beverage. J. Agric. Food Chem. 2007, 55, 7886-7890. [CrossRef] [PubMed]

3. Hainida, K.I.; Amin, I.; Normah, H.; Mohd.-Esa, N. Nutritional and amino acid contents of differently treated Roselle (Hibiscus sabdariffa L.) seeds. Food Chem. 2008, 111, 906-911. [CrossRef]

4. Cisse, M.; Dornier, M.; Sakho, M.; Ndiaye, A.; Reynes, M.; Sock, O. Le Bissap (Hibiscus sabdariffa L.): Composition et principals utilisations. Fruits 2009, 64, 179-193. [CrossRef]

5. Ramirez-Rodrigues, M.M.; Balaban, M.O.; Marshall, M.R.; Rousef, R.L. Hot and Cold Water Infusion Aroma Profiles of Hibiscus sabdariffa: Fresh Compared with Dried. J. Food Sci. 2011, 6, 212-217. [CrossRef] [PubMed]

6. Functional Foods and Drinks (FFD). A Global Strategic Business Report; Global Industry Analysts, Inc.: San Jose, CA, USA, 2007. 
7. Bechoff, A.; Cissé, M.; Fliedel, G.; Declemy, A.-L.; Ayessou, N.; Akissoe, N.; Touré, C.; Bennett, B.; Pintado, M.; Pallet, D.; et al. Relationships between anthocyanins and other compounds and sensory acceptability of Hibiscus drinks. Food Chem. 2014, 148, 112-119. [CrossRef] [PubMed]

8. Blackwell, R.; Miniard, P.; Engel, J. Consumer Behavior, 10th ed.; Thomson south-western: Mason, $\mathrm{OH}$, USA, 2006.

9. Sparke, K.; Menrad, K. Cross-European and Functional Food related consumer segmentation for new product development. J. Food Prod. Mark. 2009, 15, 213-220. [CrossRef]

10. Sabbe, S.; Verbeke, W.; Deliza, R.; Matta, V.; van Damme, P. Effect of a health claim and personal characteristics on consumer acceptance of fruit juices with different concentrations of açaí (Euterpe oleracea Mart.). Appetite 2009, 53, 84-92. [CrossRef] [PubMed]

11. Vidigal, M.; Minim, V.; Carvalho, N.; Milagres, M.; Gonçalves, A. Effect of a health claim on consumer acceptance of exotic Brazilian fruit juices: Açaí (Euterpe oleracea Mart.), Camu-camu (Myrciaria dubia), Cajá (Spondias lutes L.) and Umbu (Spondias tuberosa Arruda). Food Res. Int. 2011, 44, 1988-1996. [CrossRef]

12. Verbeke, W. Functional Foods: Consumer willingness to compromise on taste for health? Food Qual. Prefer. 2006, 17, 126-131. [CrossRef]

13. Grunert, K.G. European consumers' acceptance of functional foods. Ann. N. Y. Acad. Sci. 2011, 1190, $166-173$. [CrossRef] [PubMed]

14. Austin, I. Preference Structure Measurement: Conjoint Analysis and Related Techniques, 2nd ed.; American Marketing Association: Chicago, IL, USA, 2000.

15. Morgan, D. Focus Groups a Qualitative Research; Sage publications: Thousand Oaks, CA, USA, 1997.

16. ESOMAR - Guidelines to Determine Socio-Economic Classification. Available online: http://www.esomar. org (accessed on 1 July 2015).

17. Finco, F.; Deliza, R.; Rosenthal, A.; Silca, C. The Effect of Extrinsic Product Attributes of Pineapple Juice on Consumer Intention to Purchase. J. Int. Food Agribus. Mark. 2010, 22, 125-142. [CrossRef]

18. Bech-Larsen, T.; Grunert, K. The perceived healthiness of functional foods: A conjoint study of Danish, Finnish and American consumers' perception of functional foods. Appetite 2003, 40, 9-14. [CrossRef]

19. Gil, J.; Sanchez, M. Consumer preferences for wine attributes: A conjoint approach. Br. Food J. 1997, 99, 3-11. [CrossRef]

20. Quester, P.; Smart, J. The influence of consumption situation and product involvement over consumers use of product attribute. J. Consum. Mark. 1998, 15, 220-238. [CrossRef]

21. Moskowitz, H.; Silcher, M.; Beckeley, J.; Minkus-McKenna, D.; Mascuch, T. Sensory benefits, emotions and usage patterns for olives: Using internet-based conjoint analysis and segmentation to understand patterns of response. Food Qual. Prefer. 2005, 16, 369-382. [CrossRef]

22. Hersleth, M.; Lengard, V.; Verbeke, W.; Guerrero, L.; Naes, T. Consumers acceptance of innovations in dry-cured ham: Impact of reduced salt content, prolonged aging time and new origin. Food Qual. Prefer. 2011, 22, 31-41. [CrossRef]

23. Cardello, A.; Schutz, H.; Lesher, L. Consumer perceptions of foods processed by innovative and emerging technologies: A conjoint analytic study. Innov. Food Sci. Emerg. Technol. 2007, 8, 73-83. [CrossRef]

24. Mahanna, K.; Moskowitz, H.R.; Lee, S.Y. Assessing consumer expectations for food bars by conjoint analysis. J. Sens. Stud. 2009, 24, 851-870. [CrossRef]

25. Malhotra, N.K. Marketing Research an Applied Orientation, 2nd ed.; Prentice-Hall International, Inc.: Englewood Cliffs, NJ, USA, 1996.

26. Mesías, F.; Carrasco-Martínez, F.; Martínez, J.M.; Gaspar, P. Functional and organic eggs as an alternative to conventional production: A conjoint analysis of consumer's preferences. J. Sci. Food Agric. 2011, 91, 532-538. [CrossRef] [PubMed]

27. Lilien, G.; Rangaswamy, A.; De Bruyn, A. Principles of Marketing Engineering; Trafford: Victoria, BC, Canada, 2007; pp. 49-77.

(C) 2016 by the authors; licensee MDPI, Basel, Switzerland. This article is an open access article distributed under the terms and conditions of the Creative Commons Attribution (CC-BY) license (http://creativecommons.org/licenses/by/4.0/). 